\title{
HIV Vulnerability and Coexisting Psychosocial Health Problems among Tanzanian Men who have Sex with Men from the Perspective of an African Syndemic Model
}

\author{
Adeniyi Adeboye ${ }^{1 *}$, Michael W Ross ${ }^{2}$, Michael J Wilkerson ${ }^{1}$, Andrew Springer ${ }^{1}$, Hycienth Ahaneku ${ }^{3}$, Rafeek A Yusuf ${ }^{3}$, Titilope O Olanipekun ${ }^{3}$ \\ and Sheryl McCurdy
}

${ }^{1}$ Department of Health Promotion and Behavioral Sciences, The University of Texas School of Public Health, Houston, USA

2Program in Human Sexuality, Department of Family Medicine and Community Health, University of Minnesota, Minneapolis, USA

${ }^{3}$ Department of Epidemiology, Human Genetics and Environmental Sciences, The University of Texas School of Public Health, Houston, USA

\begin{abstract}
This study, conducted among men who have sex with men (MSM) in sub-Saharan Africa (SSA), sought to replicate the syndemic effects of psychosocial health problems on HIV risk by using data collected from a sample of $300 \mathrm{MSM}$ and bisexuals from Tanzania. We also sought to test the utility of syndemic theory by replicating the effects of the number of syndemic conditions on HIV risk behavior in that population.

Five psychosocial health problems (i.e., the syndemic factors), acronymized as SAVID, were examined: substance use while having condomless sexual intercourse, childhood and adolescent sexual abuse, experience of anti-gay violence, internalized homonegativity $(\mathrm{IH})$, and depression. Nine of the 10 odds ratios (ORs) generated from analysis of the bivariate associations between these syndemic factors were found to be statistically significant and positive; the tenth was marginally significant and positive. These results indicate not only a high degree of coexistence of the syndemic factors but also suggest that possible interactions between these factors may have additive effects on the behavioral health outcomes of the study participants. Such additive effects were confirmed by finding a "dose-response" relationship between HIV risk-associated sexual behavior and the number of the five syndemic factors reported by each participant. After controlling for demographic and contextual factors, we found that the SAVID syndemic variable significantly increased the odds of engaging in condomless sexual intercourse (OR, 1.48). This substantiates the central tenet of syndemic theory, which is that those participants who were exposed to a greater number of the psychosocial health problems also engaged in higher-risk sexual behavior.
\end{abstract}

Multivariate regression analyses revealed not only the effect of two of the syndemic conditions (substance use during sex and $\mathrm{IH}$ ) on HIV risk-related sexual behavior but also confirmed how one demographic variable (younger age) and one culturally structured factor (being gay but still having a meaningful sexual relationship with women) uniquely contributed to syndemic conditions among Tanzanian MSM.

These results suggest that a multifaceted HIV intervention grounded in syndemic theory should be considered as an effective approach to mitigating the risk environment that potentiates the vulnerability to HIV among Tanzanian MSM.

Keywords: Men that have sex with men; MSM; HIV/AIDS; Syndemic Africa

\section{Introduction}

In all contexts where surveillance of HIV risks has been carried out, results have shown that socially marginalized and disadvantaged subpopulations-both men and women-who have sex with men (MSM) have a greater risk of acquiring and transmitting HIV infection than the general population has. A critical look at the distribution patterns of HIV risk among these subpopulations intuitively suggests that those risks are not randomly distributed in the general population, which underscores the concept that a risk disparity exists. For example, a greater number of HIV risks have been documented among MSM residing in low-income African countries than in middle-income countries [1]. Similarly, Ross et al. employed political-economic analysis to document that more HIV risk-taking behaviors exist among MSM residing in countries with a high Gini coefficient (a widely used measure of inequality] and a less-affirmative political climate than they do among MSM residing in countries with a low Gini coefficient and a strongly affirmative political climate [2]. Baral and colleagues also revealed higher rates of HIV prevalence among MSM in countries that have criminalized same-sex relationships [3].

Further, various epidemiologic studies of HIV-risk behavior have documented quantifiable data on the risks of condomless anal intercourse (both receptive and insertive), transactional sex, and sex with multiple partners, which are associated with HIV transmission and acquisition. However, those studies neglected to consider the fact that risks are not discrete events that can be understood by using static descriptions [4-7]. This criticism widens the scope of HIV risks in three ways through the concept of social vulnerability grounded in a few theoretical perspectives that underscore social disparities as a comprehensive approach to elucidating various HIV risks. First, on the basis of results from comprehensive studies on vulnerability, it is known that the HIV risk of condomless anal sex, like any other risk, is not a static event but is instead a complex dynamic practice that needs to be contextualized to better understand why MSM are more

*Corresponding author:Adeniyi Adeboye, Department of Health Promotion and Behavioral Sciences, The University of Texas School of Public Health, Houston, Texas, USA, Tel: +447960266152; E-mail: adeboye05@yahoo.co.uk

Received July 24, 2017; Accepted August 27, 2017; Published August 29, 2017

Citation: Adeboye A, Ross MW, Wilkerson MJ, Springer A, Ahaneku H, et al. (2017) HIV Vulnerability and Coexisting Psychosocial Health Problems among Tanzanian Men who have Sex with Men from the Perspective of an African Syndemic Model. J Health Educ Res Dev 5: 234. doi: 10.4172/2380-5439.1000234

Copyright: @ 2017 Adeboye A, et al. This is an open-access article distributed under the terms of the Creative Commons Attribution License, which permits unrestricted use, distribution, and reproduction in any medium, provided the original author and source are credited. 
Citation: Adeboye A, Ross MW, Wilkerson MJ, Springer A, Ahaneku H, et al. (2017) HIV Vulnerability and Coexisting Psychosocial Health Problems among Tanzanian Men who have Sex with Men from the Perspective of an African Syndemic Model. J Health Educ Res Dev 5: 234. doi: $10.4172 / 2380-5439.1000234$

Page 2 of 9

vulnerable to HIV infection than others [7]. For example, despite the protective effect of the consistent use of condoms, condomless anal sex is still the greatest risk factor identified for HIV transmission among MSM [8]. However, the literature is full of empiric data confirming that a wide gap exists between the perception of HIV risks and the preventive measures practiced by MSM in countries in sub-Saharan Africa (SSA). For example, Johnston et al. who conducted a study among MSM in Zanzibar, confirmed that a high level of awareness of HIV risk-related sexual behavior existed among the participants: in $80 \%$ of those who inject drugs of abuse and in $65.60 \%$ of those who do not [9]. Another study, conducted by Nyoni and Ross among MSM in Dar es Salaam, another city in Tanzania, confirmed the existence of this unhealthy wide gap between the high perception of HIV risk and safe sexual practices among two thirds of the participants [10]. These findings substantively suggest that HIV risk-related sexual behaviors are complex and not based on rational choices informed by reasoned persuasion or on the quality of information available but instead are plausibly exerted on individuals by external social forces [11]

Second, both general studies on vulnerabilities and those specifically related to HIV conducted among various disadvantaged populations have revealed that risk factors rarely occur in isolation but are clustered in multiple forms within a milieu named "spaces of vulnerability" and "risk environments" [12-14]. The latter group defined these as "the space[s], whether social or physical, in which a variety of factors exogenous to the individual interact to increase vulnerability to HIV." This description typifies the world of most African MSM, in which they are subjected to draconian laws prohibiting same-sex relationships, with penalties ranging from life imprisonment for gay sex to civil punishment for supporters of sexual minorities and, in seven countries, to death [15]. This upstream structural factor of vulnerability has been determined to heighten HIV risk through internalized homonegativity (IH) among Ugandan [16,17] and Tanzanian MSM [18].

Third, taken together, risks not only cluster in multiple forms but also interact additively and synergistically to heighten health outcomes among socially marginalized people [19-21]. One theoretical perspective that underscores these salient attributes of risks as nonrandomly distributed, nondiscrete, multiply co-occurring factors that interact synergistically to further heighten disease burden among socially marginalized people is called "syndemic theory." Singer et al. stated that "in syndemics, the interaction of diseases or other health problems commonly arises because of adverse social conditions that put socially devalued groups at heightened risk" [22]. Considerable compelling evidence has revealed the syndemic induction of both HIV infection and HIV risk-related sexual behavior in an American sample of MSM, but no study has been conducted to date among MSM in SSA to explore similar trends [23-26].

For example, in an analysis of data obtained from MSM in four major American cities in the Urban Men's Health Study, Stall et al. found that partner violence, substance abuse, childhood sexual abuse (CSA), and depression were not only positively associated with each other but also had a "dose-response" relationship with HIV infection and HIV risk-related sexual behavior [25]. Mustanski et al. and Klein later replicated these findings in an American sample of MSM and found that interactions among psychosocial health problems increased the odds of participation in condomless anal sex $[13,26]$. It is also noteworthy that syndemic theory was applied by McCarthy et al. for the first time among MSM in Bangkok, Thailand, by Jie et al. among MSM in China, and more recently, by Pitpitan et al. among marginalized South African women [27-29]. These investigators all documented the existence of a dose-response syndemic relationship between psychosocial health problems and condomless sexual intercourse.

\section{Preliminary Evidence of Syndemic Conditions and HIV Vulnerability among MSM in SSA}

Although syndemic production of HIV risks has not been explored among MSM in SSA, Pitpitan et al. demonstrated the utility of the syndemic theory to elucidate the underlying factors that coexist and synergistically predict higher sexual risk behavior among socially marginalized women residing in impoverished and high-risk areas of South Africa [29]. The theory's utility was shown when these investigators found that seven psychosocial health problems-food insufficiency, depression, post-traumatic stress disorder, childhood abuse, violence, drug abuse, and drinking problems-coexist and additively increase the odds of condomless sex acts among South African women.

Although research conducted to date among MSM in countries in SSA has not examined the additive effect of psychological health problems on HIV risks, it has emphasized that statistically significant relationships exist between specific health problems and HIV risktaking behavior and infection. For example, Anderson et al. found a significant relationship between stigma-related violence and the number of sex partners among Tanzanian MSM [18]. Further, Ross et al. documented a large amount of condomless sexual intercourse among Ugandan MSM that was significantly associated with IH. Synthesis of the evidence has consistently documented that stigma is a major determinant of HIV vulnerability in SSA [3,30,31]. In addition, a history of forced sex and alcohol consumption were found by Aho et al. to be significantly associated with condomless anal sex among MSM in Abidjan, Ivory Coast [32].

\section{HIV Risk-Taking Behavior in African Cultural Contexts: African Syndemic Model}

Emerging themes from ethnographic studies on homosexuality in Africa have confirmed a striking difference between the African concept of homosexuality and the Western idea of sexuality $[33,34]$. There is increasing recognition that HIV risk-related sexual behaviors are contextually based, especially within the strong African sociocultural contexts. For example, synthesis of data from anthropologic studies of African homosexuals has documented the pervasiveness within African societies of patriarchal hegemony, heterosexism, religious beliefs, and gendered, transgenerational, and nonegalitarian relationships [33].

In Tanzania, as in other Swahili-speaking countries, gender roles constitute an essential but complex social institution that governs everything in the realms of sexual roles, sexual acts, work, attire, and status [35]. For example, the term "Mashoga," connotatively gendered, is ethnographically defined by Shepherd as indicating a "younger, poorer man who takes the passive role in sex with an older, wealthier Mobasha and it is generally only the person who is paid who is called Mashoga" [35]. Thus, different patterns of African same-sex relationships, characterized by unequal statuses with asymmetric power distribution, are shaped by social forces like class, rank, wealth, and age, thereby making safe-sex negotiations unattainable. Therefore, whereas sexual roles are biologically determined among heterosexuals, among Tanzanian MSM they are strictly defined by gender roles and status.

It is intuitive that the dynamics of gender roles and power in sexual relationships may also underpin the disproportionate occurrence of 
Citation: Adeboye A, Ross MW, Wilkerson MJ, Springer A, Ahaneku H, et al. (2017) HIV Vulnerability and Coexisting Psychosocial Health Problems among Tanzanian Men who have Sex with Men from the Perspective of an African Syndemic Model. J Health Educ Res Dev 5: 234. doi: $10.4172 / 2380-5439.1000234$

Page 3 of 9

receptive anal intercourse over that of insertive anal intercourse. For example, Mmbaga et al. reported the occurrence of $57.3 \%$ receptive and only $16.0 \%$ insertive anal intercourse among MSM in Dar es Salaam, Tanzania [36]. Magesa et al. in South Africa and Dunkle et al. in Tanzania also documented that higher numbers of MSM engage in receptive ("bottom") than in insertive anal sex; interpretation of this suggests the role played by gender in sexual positioning [15]. Dahoma et al. also reported that more Tanzanian MSM engage in inconsistent condom use during receptive anal sex $(90.8 \%)$ than they do during insertive anal sex (85.5\%) [8]. The public health implication of this gendered sexual practice was substantively established by Beyrer et al. who confirmed that the high probability of HIV transmission per act through the practice of receptive anal intercourse plays a central role in explaining the disproportionate disease burden in MSM [37]. It is not surprising that Ross et al. later found that condomless receptive anal intercourse is significantly associated with sexually transmitted infections among MSM in Tanzania [38].

Similarly, the strong African cultural value placed on procreation and the existence of societal homophobia may generate pressure that could explain why many MSM in SSA have outwardly adopted a heterosexual orientation by marrying and having meaningful sexual relationships with women. This subgroup of non-gay-identified MSM in SSA has been described by many AIDS researchers as serving as a bridge for the transmission of HIV within the general population $[36,39]$.

When taken together, these contextual factors may offer a better picture of how African sociocultural contexts could be shaping the high prevalence of HIV risk-related sexual behaviors among MSM in SSA, but they may also justify the need to suggest an African syndemic model as a culturally sensitive framework to use in investigating the syndemic production of those behaviors among that subpopulation.

Tanzanian MSM, like those in any other resource-constrained and rights-challenged SSA countries, are confronted by healthrelated adversities contextualized by strong cultural values in rightschallenged and pervasively homophobic environments. Hence, it would not be surprising to find that HIV risk-related sexual behavior (such as condomless anal sex) among Tanzanian MSM is an extension of syndemic conditions arising in this environment of extreme vulnerability.

This syndemic is not just the confluence of substance abuse, CSA, violence, $\mathrm{IH}$, and depression (acronymized as SAVID) but rather it is the additive and synergistic way in which these five individual epidemics interact to impose an excessive behavioral health outcome (condomless anal sex) on a vulnerable population. Because syndemic theory holds that social disparity heightens the risk of epidemics among "socially devalued groups", it is imperative to examine the effects of the syndemic SAVID on HIV risk-related sexual behaviors among Tanzanian MSM in the framework of an African syndemic model [40]. Locating SAVID in such a model leads to a high propensity to also identify sociocultural factors driving the HIV/AIDS epidemic among that population. More importantly, in the advocacy arena, a research agenda grounded in the sociocultural concept of syndemics may play a major role in informing policy-makers that structural violence may be critical in heightening HIV risk-related sexual behavior among Tanzanian MSM. This may also aid in identifying an appropriate culturally sensitive, evidence-based preventive program that will meet the public health needs of MSM in Tanzania.

To add to the existing body of literature grounded in syndemic theory, we sought to replicate the effects of a number of syndemic psychosocial health conditions on the prevalence of condomless sexual intercourse among a sample of Tanzanian MSM and bisexuals residing in this high-risk environment.

One of the tenets of syndemic theory-the clustering of syndemic conditions-led us to hypothesize that bivariate associations among the five psychosocial problems termed SAVID would be both positive and statistically significant. Also, consistently with syndemic theory, we hypothesized that there is a dose-response relationship between the number of syndemic conditions and HIV risk-related sexual behavior and that the SAVID syndemic variable is significantly associated with condomless sexual intercourse. To the best of our knowledge, this is the first study to examine the syndemic production of HIV risk-related sexual behavior among MSM in an African setting.

\section{Methods}

Data collected in a cross-sectional survey of MSM in two cities in Tanzania in 2012 and 2013 were used for this exploratory analysis. Dar es Salaam, one of the major cities in Tanzania, has an estimated population of 3 million, and Tanga, a provincial city north of Dar es Salaam, close to the border with Kenya, has an estimated population of less than half a million. Using a respondent-driven sampling method previously described by Ross et al. 200 MSM were recruited from Dar es Salaam and 100 from Tanga to participate in this study [41].

The institutional review boards at both The University of Texas Health Science Center (HSC-SPH-10-0033) and the Tanzanian National Institute for Medical Research (NIMR/HQ/R.8a/Vol. IX/1088) reviewed and approved this study.

\section{Measures}

\section{Dependent variable}

The primary outcome for this study was constructed as "ever had condomless sexual intercourse," a dichotomized variable derived from the participants' self-reported sexual practices during the 6 months prior to the survey. "Condomless" was defined as not having used condoms during any vaginal or any receptive or insertive anal sexual intercourse. The variable was a count of the number of times the participant had engaged in condomless sexual intercourse with casual partners as well as commercial sex workers.

\section{Independent variables}

Demographic variables: We examined the sociodemographic characteristics age, employment status, income, and level of education attained.

Syndemic factors: Each of the following factors has been found to contribute to a syndemic effect on sexual risk and/or HIV serostatus in previous studies [25,29].

a. Substance use during sex: Participants' answers to the following two-part question developed specifically for this study were considered: "How many of those times that you received anal sex and/or had insertive anal sex with all partners and did not use a male condom were you high or drunk?" The sum of the answers to the two separate questions formed the variable.

b. Childhood sexual abuse: CSA was defined according to the developmental classification system of Doll and colleagues, which considers an experience to be abusive depending on the age of the child or adolescent, the difference in age between the partners (i.e., 
Citation: Adeboye A, Ross MW, Wilkerson MJ, Springer A, Ahaneku H, et al. (2017) HIV Vulnerability and Coexisting Psychosocial Health Problems among Tanzanian Men who have Sex with Men from the Perspective of an African Syndemic Model. J Health Educ Res Dev 5: 234. doi: $10.4172 / 2380-5439.1000234$

peer vs. non-peer contacts), whether anal penetration occurred, and whether force was involved (any contact involving the use of force was considered to be sexual abuse regardless of participants' age) [42]. Participants were asked specific questions: "Have you ever been forced or coerced to have sex with someone?" "How old were you when you were forced or coerced into having sexual contact with someone?" "How old was the person who first forced you or coerced you into having sexual contact?" "Was your first sex partner a man or woman?" and "How old was your first sex partner?" The responses to these questions identified participants who must have experienced or had a history of CSA.

c. Level of experience of anti-gay violence: The items used to establish the level of violence were created specifically for this study. The responses of each participant to questions about the four types of abuse (physical violence or abuse and verbal, moral, and sexual abuse) could be "Yes," "No," or "No response." The questions were asked separately, so a maximum score of 4 was possible. The level of anti-gay violence was then summed up and dichotomized: a high level was characterized as three or four "Yes" answers, and a low level was characterized as two or fewer "Yes" answers.

d. Stigma, as indicated by IH score: IH is defined as the acceptance and internalization of negative attitudes toward one's own sexual orientation [43]. This was measured by using an 8-item short version of the 28-item Reactions to Homosexuality Scale [44,45]. The 8-item version is formatted with a 6-point Likert scale of responses from 0 (strongly disagree) to 5 (strongly agree). Thus, the score can range between 0 and 40 . This scale is reliable and has been validated in MSM populations in $[2,44]$.

e. Depression: Depression was measured by using the Patient Health Questionnaire-9 scale. The PHQ-9 is a validated instrument that measures the nine diagnostic criteria for DSM-IV (the diagnostic and Statistical Manual of Mental Disorders) depressive disorders [46]. It has been found reliable and valid for establishing a criterion-based diagnosis of the DSM-IV depressive disorders and for measuring the severity of depression [47]. The subject is asked to score each of the nine DSM-IV depressive symptoms between 0 (not present at all) and 3 (present nearly every day); Thus, the total score ranges between 0 and 27. The PHQ-9 has been used in SSA and has been shown to be reliable and valid $[46,48]$.

f. The SAVID syndemic: This syndemic comprises all five factors just listed. Our grouping of MSM followed the same pattern employed by Stall et al. a variable to describe the SAVID syndemic was created by categorizing each participant into one of the following four mutually exclusive groups according to the number of these factors they reported having experienced: (1) none, (2) one, (3) two, and (4) three or more [25].

Culturally relevant factors: These two items have also been used in MSM in Africa and found to be reliable [38].

a. Being gay but still having a meaningful sexual relationship with women. To determine this factor, each participant was asked to identify his status among the three types of sexual orientation, the first three of which are "gay," "straight," and "bisexual." Among those who identified as "gay" but answered "Yes" to this question: "have you ever had a meaningful sexual relationship with a woman?' were categorized as "being gay but still having meaningful sexual relationship with women". This variable was dichotomized between "Yes" and "No".

b. Importance of religion. This factor was measured by the answer to the question, "How important is your religion to you?" Possible answers ranged from $1=$ very important to $5=$ not important at all. Then the participants' answers were dichotomized as either High and or Low importance. A high level was characterized by those that answered "Yes" to the first two items (very important and quite important) and a low level was characterized by those that answered "Yes" to the remaining items.

\section{Data Analysis}

Statistical analyses of the data were carried out in five stages, all consistent with methods used in previous studies grounded in syndemic theory $[13,25,29]$. First, a descriptive analysis was conducted to establish the prevalence of psychosocial health problems. Second, Pearson product-moment correlations were performed to establish the "clustering" attribute of these psychosocial health problems. Because all the SAVID conditions and the outcome variable were dichotomized, the bivariate odds ratios (ORs) for each pair of the SAVID syndemic variables were calculated. In addition, bivariate associations between all the syndemic conditions and HIV risk-related sexual behavior were examined.

Third, to test the hypothesis that there is a dose-response relationship between psychosocial health problems and HIV riskrelated sexual behavior, chi-squared testing for associations was conducted to determine the levels of and statistical significance between the HIV risk-related sexual behavior and the number of SAVID syndemic factors reported $(0,1,2$ and 3 or more). Fourth, to test for an additive effect of the SAVID syndemic, logistic regression was employed, with the SAVID syndemic as the independent variable and HIV risk-related sexual behavior as the dependent variable; all of the other factors considered (age, employment status, educational level attained, importance of religion, and being gay but still having a meaningful sexual relationship with women) were included as control variables.

Fifth, a set of multivariate logistic regression models was used to identify any factors uniquely associated with a high level of substance use during sex, CSA, experience of anti-gay violence, $\mathrm{IH}$, and depression. Because each of the models used the same set of demographic and SAVID syndemic variables, the same logistic regression model was used to predict each of the SAVID conditions and to predict HIV risk-related sexual behavior. For each model predicting a specific problem, the measure of that problem was excluded from the model. In this exploratory study designed to replicate previous studies grounded in syndemic theory, these analyses were meant to determine how demographic factors, culturally sensitive factors, and psychosocial health problems contribute uniquely to a given syndemic condition [29].

Hosmer and Lemeshow testing for goodness of fit was also performed for each model $(\mathrm{p}<0.05)$. The criteria alpha $=0.05$ and twotailed statistical significance were employed, and all analyses were carried out by using SPSS version 22 statistical software.

\section{Results}

The demographic characteristics of the 300 Tanzanian MSM and bisexuals are given in Table 1. Slightly more than half $(51.3 \%)$ of the participants were younger than age 23 years, signifying a fairly young sample. Sixty-two percent had attained a post-primary school education, and the remaining $38 \%$ had attained a primary-school education. The unemployment rate was high: $80 \%$. Most (92\%) participants reported that they never married, but $17 \%$ reported ever 
Citation: Adeboye A, Ross MW, Wilkerson MJ, Springer A, Ahaneku H, et al. (2017) HIV Vulnerability and Coexisting Psychosocial Health Problems among Tanzanian Men who have Sex with Men from the Perspective of an African Syndemic Model. J Health Educ Res Dev 5: 234. doi: $10.4172 / 2380-5439.1000234$

Page 5 of 9

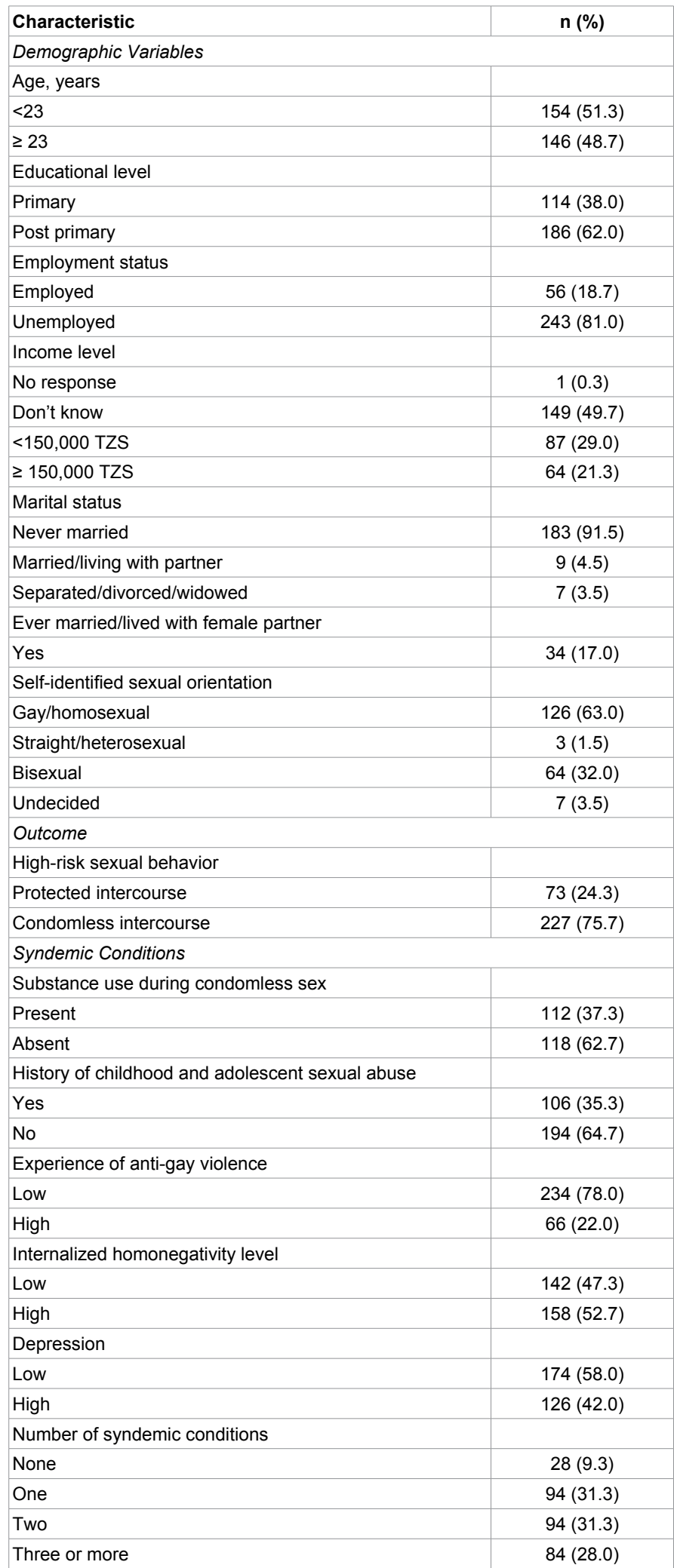

${ }^{*}$ Total sample sizes with the number of participants that have data on variables Abbreviations: MSM, men who have sex with men; TZS, Tanzanian shilling; HIV, human immunodeficiency virus.

Table 1: Demographic, HIV Risk and Social Characteristics of the 300 Tanzanian MSM in the Study Population: Tanzanian Men's Study: Dar es Salam, Tanga, 20122013. being married or living with a female partner. Also, $63 \%$ of the sample self-identified as homosexual, $32 \%$ as bisexual, $3.5 \%$ as undecided, and $1.5 \%$ as straight or heterosexual. However, $76 \%$ of the respondents reported ever having condomless sexual intercourse during the 6 months preceding the time these data were collected.

There was a high prevalence of the five psychosocial problems among the study participants: $112(37.3 \%)$ reported having been high or drunk while having condomless sexual intercourse, $106(35.3 \%)$ had a history of CSA, 66 (22\%) had experienced a high level of anti-gay violence, 158(52.7\%) screened positive for having a high level of $\mathrm{IH}$, and $126(42 \%)$ reported a high level of depression.

\section{Bivariate Associations among the Syndemic Factors}

Table 2 presents the OR for each bivariate association among the SAVID psychosocial problems. The lower portion of the table also presents the associations between the psychosocial problems and HIV risk-related sexual behavior. The results validate our hypothesis that there is a high degree of clustering of these psychosocial problems among these Tanzanian MSM: among the 10 ORs calculated between the pairs of the SAVID syndemic factors, all were positive and statistically significant except that between having IH and being drunk or high while having condomless sexual intercourse (OR, 1.00). The participants who reported being high or drunk during condomless sexual intercourse had 1.10 marginally higher odds of having experienced CSA $(\mathrm{p}<0.1)$ 1.82 higher odds of having experienced anti-gay violence $(\mathrm{p}<0.001)$, and 1.43 higher odds of having depression $(\mathrm{p}<0.01)$.

HIV risk-related sexual behavior was associated with all five SAVID syndemic psychosocial health problems, but the associations were statistically significant only among those who reported being drunk or high while having condomless sexual intercourse $(\mathrm{p}<0.001)$; they were marginally significant among those with histories of CSA, violence, and depression. For example, participants who reported relatively high percentages of condomless sex acts in the previous 6 months had 3.20 higher odds of being drunk or high while having condomless sexual intercourse $(\mathrm{p}<0.001)$.

\section{Synergistic Effects of the SAVID Psychosocial Health Problems on HIV Risk-Related Sexual Behavior}

Table 3 summarizes the combined effects of the five psychosocial problems on HIV risk-related sexual behavior. The syndemicconditions count was based on the number of psychosocial health problems reported by each respondent: $28(8.4 \%)$ reported having none, $94(29.1 \%)$ reported having one, 94 (30.0\%) reported having two, and $84(32.6 \%)$ reported having three or more of the syndemic conditions. This confirms one of the central tenets of syndemic theory, which is that a behavioral health outcome (in this case, HIV risk-related sexual behavior) is heightened by the additive effects of syndemic conditions [20]. Thus, among the Tanzanian MSM and bisexuals who ever had condomless sexual intercourse in the last 6 months prior to this study $(n=227)$, higher numbers of psychosocial problems were found to be significantly and positively associated with higher HIV risk-related sexual behavior.

However, as shown in Table 4, which presents the outcomes of the logistic regression models examining the relationship between the SAVID syndemic variable and HIV risk-related sexual behavior while controlling for both sociocultural factors (e.g., importance of religion) and demographic variables (e.g., age), among all the sociocultural and demographic variables examined in the model, only the SAVID 
Citation: Adeboye A, Ross MW, Wilkerson MJ, Springer A, Ahaneku H, et al. (2017) HIV Vulnerability and Coexisting Psychosocial Health Problems among Tanzanian Men who have Sex with Men from the Perspective of an African Syndemic Model. J Health Educ Res Dev 5: 234. doi: $10.4172 / 2380-5439.1000234$

Page 6 of 9

\begin{tabular}{|c|c|c|c|c|c|}
\hline Psychosocial problem & $\begin{array}{c}\text { Substance use during } \\
\text { sex }\end{array}$ & $\begin{array}{c}\text { Childhood and } \\
\text { adolescent } \\
\text { sexual abuse }\end{array}$ & $\begin{array}{c}\text { Experience of anti- } \\
\text { gay violence }\end{array}$ & $\begin{array}{c}\text { Internalized } \\
\text { homonegativity } \\
\text { Depression }\end{array}$ & \\
\hline Substance use during sex & - & - & \\
\hline $\begin{array}{c}\text { Childhood and adolescent } \\
\text { sexual abuse }\end{array}$ & $1.10(0.81-1.48) \dagger$ & & & \\
\hline Experience of anti-gay & $1.82(1.38-2.41) \S$ & $1.75(1.30-2.36) \ddagger$ & - & - \\
\hline Internalized homonegativity & $1.00(0.75-1.34)$ & $1.40(1.03-1.90) \ddagger$ & $2.56(1.60-4.11) \S$ & \\
\hline Depression & $1.43(1.10-1.86) \ddagger$ & $1.61(1.18-2.18) \ddagger$ & $2.76(1.75-4.40) \S$ & $1.60(1.26-2.02) \S$ & - \\
\hline HIV risk sexual behaviour & $3.20(0.56-1.14) \S$ & $1.06(0.93-2.20) \dagger$ & $1.11(0.97-1.27) \dagger$ & $1.03(0.90-1.17)$ \\
\hline
\end{tabular}

Abbreviations: HIV, human immunodeficiency virus; MSM, men who have sex with men.

${ }^{*}$ Data are presented as odds ratios (95\% confidence intervals).

$\dagger p<0.1 ; \ddagger p<0.05 ; \S p<0.01$.

Table 2: Bivariate Associations between Psychosocial Problems and HIV Sexual Risk Behavior among the 300 Tanzanian MSM in the Study Population*: Tanzanian Men's Study: Dar es Salam, Tanga, 2012-2013.

\begin{tabular}{|c|c|c|c|c|}
\hline & \multicolumn{4}{|c|}{ Number of psychosocial health problems } \\
\hline & 0 & 1 & 2 & $\geq 3$ \\
\hline & $(n=28)$ & $(n=94)$ & $(n=94)$ & $(n=84)$ \\
\hline HIV risk sexual behaviour* & $8.40 \%$ & $29.10 \%$ & $30.00 \%$ & $32.60 \%$ \\
\hline
\end{tabular}

Table 3: Number of Psychosocial Health Problems by HIV Risk Sexual Behavior among the 300 Tanzanian MSM in the Study Population: Tanzanian Men's Study: Dar es Salam, Tanga, 2012-2013.

\begin{tabular}{|l|c|c|}
\hline Predictor & Odds ratio \\
\hline Age & 1.37 & 95\% Confidence interval \\
\hline Employment & 1.23 & $0.78-2.39$ \\
\hline Education & $0.63-2.39$ \\
\hline Importance of religion & 0.88 & 0.83 \\
\hline Being gay but still having a meaningful sexual relationship with women & 1.18 \\
\hline SAVID syndemic & 1.57 \\
\hline
\end{tabular}

$\mathrm{R}^{2}=0.049$

$75.8 \%$ of cases correctly classified

Abbreviations: HIV, human immunodeficiency virus; MSM, men who have sex with men; SAVID syndemic, count of psychosocial health problems (range, $0-4$ ); ${ }^{2}$, Nagekerke R-squared statistic.

${ }^{*} \mathrm{p}<0.01$.

Table 4: Logistic regression models to evaluate the associations between the syndemic conditions and HIV risks, controlling for demographic factors, among the 300 Tanzanian MSM in the study population: Tanzanian Men's Study: Dar es Salam, Tanga, 2012-2013.

syndemic variable increased the risk of having condomless sex $(\mathrm{OR}$, $1.48 ; \mathrm{p}=0.01)$.

\section{Multivariate Regression Analyses}

In Table 5, the predictors of each of the five SAVID syndemic conditions were examined in six single, independent multivariate logistic regression models. All of the models were positive and statistically significant $(\mathrm{p}<0.05)$ according to Hosmer and Lemeshow testing for goodness of fit. Whereas Table 2 reveals that each of the syndemic conditions was independently associated with one another, Table 5 shows which specific SAVID syndemic condition is uniquely and significantly associated with a given problem after controlling for other factors in the model. For example, younger age, the importance of religion, substance use during condomless sexual intercourse, CSA, $\mathrm{IH}$, and depression were each statistically significantly associated with a higher likelihood of experiencing violence. It is interesting that being gay but still having a meaningful relationship with women, a culturally based factor, was significantly associated with $\mathrm{IH}$. In the same model, violence and depression were also found to be associated with a higher likelihood of experiencing $\mathrm{IH}$, after controlling for demographic and the other psychosocial problems. However, in this sample population, substance use during condomless sex and $\mathrm{IH}$ were the only syndemic conditions that were significantly associated with HIV risk-related sexual behavior.

\section{Discussion}

To our knowledge, this is the first study to be conducted among Tanzanian MSM and bisexuals that sought to replicate the syndemic effects of psychosocial health problems on HIV risk-related sexual behavior. We also sought to test the utility of the syndemic theory by replicating the effects of the number of syndemic conditions on such behavior among that population in SSA.

Nine of the 10 ORs generated from the bivariate associations between the five SAVID syndemic conditions were positive and statistically significant, indicating a high degree of coexistence of these psychosocial health problems among Tanzanian MSM. The additive effect of these syndemic conditions was also confirmed by finding a dose-response relationship between HIV risk-related sexual behavior and the number of coexisting psychosocial health problems. This substantiates the central tenet of syndemic theory, which says that participants who were exposed to a greater number of psychosocial health problems also engaged in more risk-related sexual behavior [25]. These findings are congruous with those of previous studies conducted among an American sample of MSM and among MSM in China and Thailand $[23,25-28,49]$.

Our findings also confirm the utility and robustness of syndemic theory as applied to MSM in SSA. Placing HIV risk-related sexual behavior within the context of syndemic conditions offers a better 
Citation: Adeboye A, Ross MW, Wilkerson MJ, Springer A, Ahaneku H, et al. (2017) HIV Vulnerability and Coexisting Psychosocial Health Problems among Tanzanian Men who have Sex with Men from the Perspective of an African Syndemic Model. J Health Educ Res Dev 5: 234. doi: $10.4172 / 2380-5439.1000234$

Page 7 of 9

\begin{tabular}{|c|c|c|c|c|c|c|}
\hline Independent variable & $\begin{array}{l}\text { Substance use } \\
\text { during condom } \\
\text { less sexual } \\
\text { intercourse }\end{array}$ & $\begin{array}{c}\text { Childhood and } \\
\text { adolescent sexual } \\
\text { abuse }\end{array}$ & $\begin{array}{l}\text { Experience of anti- } \\
\text { gay violence }\end{array}$ & $\begin{array}{c}\text { Internalized } \\
\text { homonegativity }\end{array}$ & Depression & $\begin{array}{c}\text { HIV risk sexual } \\
\text { behaviour (Ever had } \\
\text { condom less sexual } \\
\text { intercourse) }\end{array}$ \\
\hline Age $<23$ years & $1.06(0.62-1.80)$ & $2.13(1.26-3.60) \dagger$ & $2.03(1.04-3.94) \dagger$ & $0.90(0.54-1.50)$ & $0.68(0.41-1.15)$ & $1.41(0.79-2.53)$ \\
\hline Employment & $0.70(0.36-1.36)$ & $0.60(0.30-1.16)$ & $1.33(0.55-3.18)$ & $1.43(0.75-2.71)$ & $1.27(0.67-0.43)$ & $1.20(0.60-2.39)$ \\
\hline Education & $0.76(0.44-1.31)$ & $1.12(0.65-1.93)$ & $1.77(0.87-3.60)$ & $1.40(0.83-2.37)$ & $0.83(0.48-1.42)$ & $0.82(0.45-1.48)$ \\
\hline $\begin{array}{l}\text { Being gay but still having } \\
\text { meaningful relationship } \\
\text { with women }\end{array}$ & $1.17(0.67-2.03)$ & $0.75(0.44-1.28)$ & $0.86(0.45-1.66)$ & $2.02(1.19-3.42) \dagger$ & $1.00(0.55-1.61)$ & $1.15(0.63-2.11)$ \\
\hline High importance of religion & $1.26(0.32-4.96)$ & $0.72(0.17-3.01)$ & $3.52(0.80-15.47) \ddagger$ & $1.18(0.28-4.98)$ & $1.46(0.35-6.17)$ & $0.87(1.70-4.53)$ \\
\hline $\begin{array}{l}\text { Substance use during } \\
\text { condom less sexual } \\
\text { intercourse }\end{array}$ & - & $1.16(0.67-2.0)$ & $2.67(1.41-5.07) \S$ & $0.71(0.41-1.20)$ & $0.64(0.38-1.10)$ & $3.01(1.55-5.79) \S$ \\
\hline $\begin{array}{c}\text { Childhood and adolescent } \\
\text { sexual abuse }\end{array}$ & $1.18(0.68-2.04)$ & - & $2.30(1.21-4.40) \dagger$ & $0.84(0.50-1.43)$ & $1.81(1.07-3.07) \ddagger$ & $1.16(0.63-2.14)$ \\
\hline $\begin{array}{c}\text { Experience of anti-gay } \\
\text { violence }\end{array}$ & $2.65(1.41-4.97) \dagger$ & $2.28(1.21-4.30) \dagger$ & - & $2.76(1.44-5.30) \dagger$ & $3.30(1.22-4.31) \ddagger$ & $1.05(0.49-2.26)$ \\
\hline Internalized homonegativity & $1.43(0.83-2.46)$ & $1.18(0.69-1.99)$ & $2.71(1.41-5.22) \S$ & - & $2.06(1.24-3.45) \dagger$ & $2.06(1.24-3.45) \dagger$ \\
\hline Depression & $1.54(0.91-2.63)$ & $1.81(1.06-3.07) \dagger$ & $2.24(1.18-4.20) \dagger$ & $2.07(1.24-3.45) \dagger$ & - & $1.36(0.74-2.49)$ \\
\hline HIV risk sexual behaviour & $3.03(1.57-5.89) \S$ & $1.15(0.63-2.11)$ & $1.00(0.47-2.30)$ & $1.02(0.57-1.82)$ & $0.73(0.40-1.33)$ & - \\
\hline
\end{tabular}

Abbreviations: MSM, men who have sex with men; HIV, human immunodeficiency virus.

*Data are presented as adjusted odds ratios (95\% confidence intervals). Each column represents a single and independent regression model. $\dagger \mathrm{p}<0.01 ; \mathrm{p}<0.05 ; \S \mathrm{p}<0.001$.

Table 5: Multivariate Regressions between Intersecting Psychosocial Problems among the 300 Tanzanian MSM in the Study Population*: Tanzanian Men's Study: Dar es Salam, Tanga, 2012-2013.

understanding of how the "risk environment" these MSM are in could potentiate HIV vulnerability among that disadvantaged subpopulation.

These analyses also substantiated the important roles that sociodemographic variables (e.g., age) and culturally sensitive factors (e.g., being gay but still having a meaningful sexual relationship with women) may play in contributing to a specific syndemic condition. For example, respondents who were younger had 2.1 higher odds of having experienced CSA $(\mathrm{p}<0.01)$ than older respondents had, and being gay but still having a meaningful sexual relationship with women was statistically significantly associated with IH. The latter subgroup has been referred to as straight-identified MSM or non-gay identified MSM. Ironically, despite the fact that these MSM may use this genderconforming behavior to avoid stigma-related violence, they are still negatively affected by societal homophobia, manifesting as $\mathrm{IH}$ [50]. Further research is needed to more fully explore this observed association, especially the different effect that societal homophobia, in the form of IH, has on non-gay identified and gay-identified MSM.

After demographic factors and other syndemic conditions were controlled for, our results showed that HIV risk-related behavior was significantly associated with substance use while having condomless sexual intercourse and with positivity for $\mathrm{IH}$. Although previous studies found a significant relationship between HIV risk-related behavior and a reported history of CSA, this study did not confirm such a relationship. It may be that this type of relationship is indirect and complex, requiring another deterministic mechanism that lies outside the scope of this study [51-56].

Some limitations need to be considered while interpreting the findings from this study. Although respondent-driven sampling, a non-biased sampling method, was used to recruit the participants for our study, that method is nonprobabilistic and thus reduces the generalizability of these findings. Further, some of the factors we measured and analysed-such as having a history of CSA and ever having had condomless sex in the 6 months before participation in the study-may also be biased because they were obtained retrospectively from the participants. Finally, the study's cross-sectional design limits the findings to a correlational level instead of identifying cause-andeffect attributions.

\section{Conclusion}

In conclusion, the results of this study confirmed both the existence of syndemic conditions among MSM living in the impoverished and homophobic environment of Tanzania and both the additive and synergistic effects that these conditions have on the behavioral health outcome of these marginalized men. The findings reinforce the relevance of considering syndemic theory when designing a multifaceted intervention to reduce HIV risk among MSM living in such a high-risk environment. When one considers the effect of different environmental levels of risk on the transmission and acquisition of HIV among the socially disadvantaged, the epidemiologic classification of MSM and others as the "most-at-risk population" may be a misnomer that possibly engenders even greater stigma; that term associates these subpopulations with HIV risk, but it neglects the underlying thematic factors that operate at different levels of "risk environment" that make these people vulnerable to HIV.

\section{References}

1. Baral S, Sifakis F, Cleghorn F, Beyrer C (2007) Elevated risk for HIV infection among men who have sex with men in low-and middle-income countries 2000 2006: A systematic review.

2. Ross MW, Kajubi P, Mandel JS, McFarland W, Raymond HF (2013) Internalized homonegativity/homophobia is associated with HIV-risk behaviours among Ugandan gay and bisexual men. International Journal of STD \& AIDS 24: 409413.

3. Fay H, Baral SD, Trapence G, Motimedi F, Umar E, et al. (2011) Stigma, health care access, and HIV knowledge among men who have sex with men in malawi, namibia, and botswana. AIDS and Behavior 15: 1088-1097.

4. Parker R (2001) Sexuality, culture, and power in HIVIAIDS research. Annua Review of Anthropology 163-179.

5. Parker R (2009) Unintended consequences: Evaluating the impact of HIV and AIDS on sexuality research and policy debates. Cadernos De Saúde Pública 25: 251-258

6. Fee E, Krieger N (1993) Understanding AIDS: Historical interpretations and 
Citation: Adeboye A, Ross MW, Wilkerson MJ, Springer A, Ahaneku H, et al. (2017) HIV Vulnerability and Coexisting Psychosocial Health Problems among Tanzanian Men who have Sex with Men from the Perspective of an African Syndemic Model. J Health Educ Res Dev 5: 234. doi: $10.4172 / 2380-5439.1000234$

the limits of biomedical individualism. American Journal of Public Health 83 : 1477-1486.

7. Delor F, Hubert M (2000) Revisiting the concept of 'vulnerability'. Social Science \& Medicine 50: 1557-1570.

8. Dahoma M, Johnston LG, Holman A, Miller LA, Mussa M, et al. (2011) HIV and related risk behavior among men who have sex with men in zanzibar, tanzania: Results of a behavioral surveillance survey. AIDS and Behavior 15: 186-192.

9. Johnston LG, Holman A, Dahoma M, Miller LA, Kim E, et al. (2010) HIV risk and the overlap of injecting drug use and high-risk sexual behaviours among men who have sex with men in zanzibar (unguja), tanzania. International Journal of Drug Policy 21: 485-492.

10. Nyoni J, Ross MW (2012) Factors associated with HIV testing in men who have sex with men, in dar es salaam, tanzania. Sexually Transmitted Infections 88 : 483

11. Latkin C, Knowlton A (2005) Micro-social structural approaches to HIV prevention: A social ecological perspective. AIDS Care 17: 102-113.

12. Masten AS, Wright MO (1998) Cumulative risk and protection models of child maltreatment. Journal of Aggression, Maltreatment \& Trauma 2: 7-30.

13. Mustanski B, Garofalo R, Herrick A, Donenberg G (2007) Psychosocial health problems increase risk for HIV among urban young men who have sex with men: Preliminary evidence of a syndemic in need of attention. Annals of Behavioral Medicine 34: 37-45.

14. Watts MJ, Bohle HG (1993) Hunger, famine and the space of vulnerability. Geojournal 30: 117-125.

15. Magesa DJ, Mtui LJ, Abdul M, Kayange A, Chiduo R, et al. (2014) Barriers to men who have sex with men attending HIV related health services in dar es salaam, tanzania. Tanzania Journal of Health Research, p: 16.

16. Semugoma P, Beyrer C, Baral S (2012) Assessing the effects of antihomosexuality legislation in uganda on HIV prevention, treatment, and care services. Journal of Social Aspects of HIVIAIDS 9: 173-176.

17. Ross MW, Berg RC, Schmidt AJ, Hospers HJ, Breveglieri M, et al. (2013) European MSM Internet Survey (EMIS) Network. Internalised homonegativity predicts HIV-associated risk behavior in European men who have sex with men in a 38-country cross-sectional study: Some public health implications of homophobia. BMJ Open.

18. Anderson AM, Ross MW, Nyoni JE, McCurdy SA (2015) High prevalence of stigma-related abuse among a sample of men who have sex with men in tanzania: Implications for HIV prevention. AIDS Care 27: 63-70.

19. Rhodes $T$ (2002) The 'risk environment': A framework for understanding and reducing drug-related harm. International Journal of Drug Policy 13: 85-94.

20. Singer M, Clair S (2003) Syndemics and public health: Reconceptualizing disease in bio-social context. Medical Anthropology Quarterly 423-441.

21. Barnett T, Whiteside A (1999) HIVIAIDS and development: Case studies and a conceptual framework. The European Journal of Development Research 11: 200-234

22. Singer MC, Erickson PI, Badiane L, Diaz R, Ortiz D, et al. (2006) Syndemics, sex and the city: Understanding sexually transmitted diseases in social and cultural context. Social Science \& Medicine 63: 2010-2021.

23. O'Leary A, Jemmott JB, Stevens R, Rutledge SE, Icard LD (2014) Optimism and education buffer the effects of syndemic conditions on HIV status among african american men who have sex with men. AIDS and Behavior 18: 20802088

24. Dyer TP, Shoptaw S, Guadamuz TE, Plankey M, Kao U, et al. (2012) Application of syndemic theory to black men who have sex with men in the multicenter AIDS cohort study. Journal of Urban Health 89: 697-708.

25. Stall R, Mills TC, Williamson J, Hart T, Greenwood G, et al. (2003) Association of co-occurring psychosocial health problems and increased vulnerability to HIVIAIDS among urban men who have sex with men. American Journal of Public Health 93: 939-942.

26. Klein H (2011) Using a syndemics theory approach to study HIV risk taking in a population of men who use the internet to find partners for unprotected sex. American Journal of Men's Health 5: 466-476.

27. McCarthy K, Wimonsate W, Guadamuz T, Varangrat A, Thienkrua W, et al. (2010) Syndemic analysis of co-occurring psychosocial health conditions and
HIV infection in a cohort of men who have sex with men (MSM) in bangkok thailand. International AIDS Conference 18-23.

28. Jie W, Ciyong L, Xueqing D, Hui W, Lingyao H (2012) A syndemic of psychosocial problems places the MSM (men who have sex with men) population at greater risk of HIV infection. PloS One 7: e32312.

29. Pitpitan EV, Kalichman SC, Eaton LA, Cain D, Sikkema KJ, et al. (2013) Co-occurring psychosocial problems and HIV risk among women attending drinking venues in a south african township: A syndemic approach. Annals of Behavioral Medicine 45: 153-162.

30. Berg RC, Ross MW, Weatherburn P, Schmidt AJ (2013) Structural and environmental factors are associated with internalised homonegativity in men who have sex with men: Findings from the european MSM internet survey (EMIS) in 38 countries. Social Science \& Medicine 78: 61-69.

31. Smith AD, Tapsoba P, Peshu N, Sanders EJ, Jaffe HW (2009) Men who have sex with men and HIVIAIDS in sub-saharan africa. The Lancet 374: 416-422.

32. Aho J, Hakim A, Vuylsteke B, Semde G, Gbais HG, et al. (2014) Exploring risk behaviors and vulnerability for HIV among men who have sex with men in abidjan, cote d' ivoire: Poor knowledge, homophobia and sexual violence.

33. Murray SO, Roscoe W (1998) Boy-wives and female-husbands: Studies in African homosexualities.

34. McAllister J (2013) Tswanarising global gayness: The 'unAfrican'argument, western gay media imagery, local responses and gay culture in botswana. Culture, Health \& Sexuality 15: 88-101.

35. Amory DP (1997) "Homosexuality" in africa: Issues and debates. Issue: A Journal of Opinion 5: 10

36. Mmbaga EJ, Dodo MJ, Leyna GH, Moen K, Leshabari MT (2012) Sexual Practices and Perceived Susceptibility to HIV Infection among Men who have Sex with Men in Dar Es Salaam, Mainland Tanzania. J AIDS Clinic Res S1: 012.

37. Beyrer C, Baral SD, van Griensven F, Goodreau SM, Chariyalertsak S, et al. (2012) Global epidemiology of HIV infection in men who have sex with men. The Lancet 380: 367-377.

38. Ross MW, Nyoni J, Ahaneku HO, Mbwambo J, McClelland RS, et al. (2014) High HIV seroprevalence, rectal STIs and risky sexual behaviour in men who have sex with men in dar es salaam and tanga, tanzania. BMJ Open 4 e006175.

39. Morris M, Kretzschmar M (1997) Concurrent partnerships and the spread of HIV. Aids 11: 641-648.

40. Rhodes T, Singer M, Bourgois P, Friedman SR, Strathdee SA (2005) The socia structural production of HIV risk among injecting drug users. Social Science \& Medicine 61: 1026-1044

41. Ross MW, Rosser B (1996) Measurement and correlates of internalized homophobia: A factor analytic study. Journal of Clinical Psychology 52: 15-21.

42. Doll LS, Joy D, Bartholow BN, Harrison JS, Bolan G, et al. (1992) Self-reported childhood and adolescent sexual abuse among adult homosexual and bisexual men. Child Abuse \& Neglect 16: 855-864.

43. Shidlo A (1994) Internalized homophobia: Conceptual and empirical issues in measurement. Some of the Information in this Chapter was Presented at the Meeting of the American Psychological Assn, New York.

44. Ross MW, Smolenski DJ, Kajubi P, Mandel JS, McFarland W, et al. (2010) Measurement of internalized homonegativity in gay and bisexual men in uganda: Cross-cultural properties of the internalized homonegativity scale. Psychology, Health \& Medicine 15: 159-165.

45. Smolenski DJ, Diamond PM, Ross MW, Rosser BS (2010) Revision, criterion validity, and multigroup assessment of the reactions to homosexuality scale. Journal of Personality Assessment 92: 568-576.

46. Adewuya AO, Ola BA, Afolabi OO (2006) Validity of the patient health questionnaire (PHQ-9) as a screening tool for depression amongst nigerian university students. Journal of Affective Disorders 96: 89-93.

47. Kroenke K, Spitzer RL, Williams JB (2001) The Phq-9. Journal of General Internal Medicine 16: 606-613.

48. Monahan PO, Shacham E, Reece M, Kroenke K, Ong'or WO, et al. (2009) Validity/reliability of PHQ-9 and PHQ-2 depression scales among adults living with HIVIAIDS in western kenya. Journal of General Internal Medicine 24: 189-197. 
Citation: Adeboye A, Ross MW, Wilkerson MJ, Springer A, Ahaneku H, et al. (2017) HIV Vulnerability and Coexisting Psychosocial Health Problems among Tanzanian Men who have Sex with Men from the Perspective of an African Syndemic Model. J Health Educ Res Dev 5: 234. doi: $10.4172 / 2380-5439.1000234$

49. Shoptaw S, Weiss RE, Munjas B, Hucks-Ortiz C, Young SD, et al. (2009) Homonegativity, substance use, sexual risk behaviors, and HIV status in poor and ethnic men who have sex with men in los angeles. Journal of Urban Health 86: 77-92.

50. Lane T, Mogale T, Struthers H, McIntyre J, Kegeles SM (2008) "They see you as a different thing": The experiences of men who have sex with men with healthcare workers in south african township communities. Sexually Transmitted Infections 84: 430-433.

51. Arreola SG, Neilands TB, Diaz R (2009) Childhood sexual abuse and the sociocultural context of sexual risk among adult latino gay and bisexual men. American Journal of Public Health 99: 432-438.

52. Catania JA, Paul J, Osmond D, Folkman S, Pollack L, et al. (2008) Mediators of childhood sexual abuse and high-risk sex among men-who-have-sex-withmen. Child Abuse \& Neglect 32: 925-940.
53. Carey JW, Mejia R, Bingham T, Ciesielski C, Gelaude D, et al. (2009) Drug use, high-risk sex behaviors, and increased risk for recent HIV infection among men who have sex with men in chicago and los angeles. AIDS and Behavior 13: 1084-1096.

54. Dunkle KL, Decker MR (2013) Gender - based violence and HIV: Reviewing the evidence for links and causal pathways in the general population and highrisk groups. American Journal of Reproductive Immunology 69: 20-26.

55. Füssel H (2007) Vulnerability: A generally applicable conceptual framework for climate change research. Global Environmental Change 17: 155-167.

56. Thurston IB, Dietrich J, Bogart LM, Otwombe KN, Sikkema KJ, et al. (2014) Correlates of sexual risk among sexual minority and heterosexual south african youths. American Journal of Public Health 104: 1265-1269. 